\title{
Some Examples of the Application and Validation of the NUFT Subsurface Flow and Transport Code
}

\author{
J.J. Nitao
}

August 1, 2001

U.S. Department of Energy

Lawrence

Livermore

National

Laboratory 


\section{DISCLAIMER}

This document was prepared as an account of work sponsored by an agency of the United States Government. Neither the United States Government nor the University of California nor any of their employees, makes any warranty, express or implied, or assumes any legal liability or responsibility for the accuracy, completeness, or usefulness of any information, apparatus, product, or process disclosed, or represents that its use would not infringe privately owned rights. Reference herein to any specific commercial product, process, or service by trade name, trademark, manufacturer, or otherwise, does not necessarily constitute or imply its endorsement, recommendation, or favoring by the United States Government or the University of California. The views and opinions of authors expressed herein do not necessarily state or reflect those of the United States Government or the University of California, and shall not be used for advertising or product endorsement purposes.

Work performed under the auspices of the U.S. Department of Energy by the University of California Lawrence Livermore National Laboratory under Contract W-7405-Eng-48.

This report has been reproduced directly from the best available copy.

Available to DOE and DOE contractors from the

Office of Scientific and Technical Information

P.O. Box 62, Oak Ridge, TN 37831

Prices available from (423) 576-8401

http://apollo.osti.gov/bridge/

Available to the public from the

National Technical Information Service

U.S. Department of Commerce

5285 Port Royal Rd.,

Springfield, VA 22161

http://www.ntis.gov/

OR

Lawrence Livermore National Laboratory

Technical Information Department's Digital Library

http://www.llnl.gov/tid/Library.html 


\title{
Some Examples of the Application and Validation of the NUFT Subsurface Flow and Transport Code
}

\author{
John J. Nitao \\ Geosciences and Environmental Technologies Division
}

\section{Background}

This report was written as partial fulfillment of a subcontract from DOD/DOE Strategic Environmental Research and Development Program (SERDP) as part of a project directed by the U.S. Army Engineer Research and Development Center, Waterways Experiment Station (WES), Vicksburg, Mississippi. The report documents examples of field validation of the NUFT code for environmental remediation, with emphasis on soil vapor extraction, and describes some of the modifications needed to integrate the code into the DOD Groundwater Modeling System (GMS, 2000). Note that this report highlights only a subset of the full capabilities of the NUFT code.

\section{Acknowledgements}

I would like to thank Dr. Mark Dortch at WES, without whom this work would not have been possible, and my colleagues at LLNL for kindly allowing me to include their work in this report. In alphabetical order they are: Charles R. Carrigan, Steven F. Carle, Richard B. Knapp, Reed M. Maxwell, and Andrew F.B. Tompson. I would also like to thank the following program leaders at LLNL for supporting their work and for granting permission to present these results: Roger D. Aines, Robert W. Bainer, Norman R. Burkhard, Thomas A. Buscheck, Martha Kohler, Robin L. Newmark, Gayle A. Pawloski, John J. Zucca.

This work was performed under the auspices of the U.S. Department of Energy by the University of California, Lawrence Livermore National Laboratory under Contract No. W-7405-Eng-48.

\section{Description of the NUFT Model}

NUFT (Non-isothermal Unsaturated-saturated Flow and Transport model) is a general-purpose computer code for modeling multiphase fluid flow and multi-species reactive transport in porous media under non-isothermal or isothermal conditions (Nitao, 1998). It has been used for various field applications in environmental remediation: soil vapor extraction (Nitao et al., 2000b), soil vapor extraction combined with groundwater dewatering (Rueth et al., 1998), bioventing (Sun et al., 2000), dynamic steam stripping and contaminant hydro-pyrolosis (Newmark et al., 1999), and electrical heating (Carrigan and Nitao, 2000). NUFT has also been used in field studies for research in vadose zone flow and transport processes (Lee and Nitao 2000; Carrigan, 1999), as well as for evaluation of 
vadose zone contaminated sites (Demir et al., 1999). Other field applications include nuclear waste disposal (Nitao and Buscheck, 1996), nuclear treaty verification (Carrigan et al., 1996), containment of gases during subcritical test explosions, and enhanced petroleum recovery (Sahni et al., 2000).

NUFT is a robust code that can solve highly, computationally demanding problems. It runs on IBM pc-compatibles and various Unix operating systems such as Sun Solaris, IBM AIX, HP-UX, DEC $\mathrm{OSF}$, and 386 Linux. The input file format is highly flexible. The code is written in the $\mathrm{C}++$ language. Because it uses dynamically allocated memory, the code does not have to be recompiled for different problem dimensions.

NUFT consists of several modules contained in a single source code. Each module has its own set of simplifying assumptions so that the user can select the most physically appropriate mathematical module and computationally efficient numerical solution method. Some of the current modules are

UCSAT unconfined aquifer flow model,

US1P Richard's equation flow model,

US1C single component, single-phase transport model,

USNT general multiphase, multicomponent flow and transport under either isothermal or non-isothermal conditions,

JOULE electrical heating.

The distinct modules in the code utilize a common set of utility routines and input file format. The various modules are essentially isolated from each other and hence future modules can be added without affecting existing ones. Input data is in the form of that used by the Lisp language. An internal Lisp interpreter for the Scheme dialect of Lisp is part of the simulator in order to parse and store input data information, to perform input error checking, and to set default input parameter values.

USNT is the NUFT module (Nitao, 1999) that is the focus of this report. The USNT module solves the multiphase flow and multi-species flow and transport equations under non-isothermal or isothermal conditions. Local thermodynamic equilibrium for partitioning of species between fluid phases is assumed. Vapor pressure lowering of components is available as an option. A multi-porosity model is also available as an option for modeling fractured porous rock systems. Kinetic reaction rate laws can be turned on, such as first-order, power law, sequentially first-order, Monod, and dual-substrate Monod reactions.

Unlike some other multiphase codes, the NUFT-USNT module can handle full disappearance of the NAPL, or any, fluid phase, due to, for example, dissolution or evaporation. This is in contrast to some codes that require at least a small amount of NAPL to be present everywhere in the domain, which means that, for those models, the predicted groundwater concentrations can never go below the contaminant solubility.

The NUFT-USNT module solves the partial differential equations for the conservation of mass and energy using the integrated finite-difference method. An integrated finite-difference spatial discretization is used to solve the balance equations. The resulting non-linear system of equations is 
solved at each time step by the Newton-Raphson method. Each iteration of the Newton-Raphson method requires the solution of a system of linear equations arising from the linearization of the nonlinear system. Options for solution of the linear equation system are the variably-banded gaussian elimination method and the iterative conjugate gradient method with various options for preconditioners. See the NUFT Reference Manual (Nitao, 1998) and the NUFT USNT User's Manual (Nitao, 1999) for the actual balance equations and references to numerical methods. 


\section{Model Enhancements}

Monod-type reactions were implemented as part of the NUFT-USNT module in order to model bioremediation of contaminants, such as during bioventing or natural degradation. The general form of the implemented reaction law is a product of factors of the form $b_{i} /\left(b_{i}+C_{i}\right), C_{i} /\left(s_{i}+C_{i}\right)$, and $C_{i} p_{i}$ where $C_{i}$ is the concentration of the $i$-th reactant species, $b_{i}$ is the inhibition constant, $s_{i}$ is the saturation constant, and $\mathrm{p}_{\mathrm{i}}$ is some power. The index $\mathrm{i}$ can run over any set of contaminants or other mass components such as oxygen or methane. An additional temperature-dependent factor proportional to the Arrhenius-type rate law $\exp (-\mathrm{E} / \mathrm{RT})$ is also optionally present. Here, $\mathrm{R}$ is the gas constant, and $\mathrm{T}$ is absolute temperature. Documentation of the Monod rate laws using NUFT is given by Sun et al. (2000).

Another enhancement in NUFT was the capability to generate a heterogeneous field of saturated and unsaturated hydrological properties. This feature allows for more realistic modeling of remediation sites where natural heterogeneity plays an important role. In our approach the physical domain is subdivided into any number of lithological material types. Up to three statistically-independent random fields are generated for each material type. Hydrologic properties in a particular material are specified as functions of these multiple random fields so that the generated air entry pressure field, for example, can be statistically correlated with the saturated permeability field. The random fields are generated by the spectral method (Lee and Nitao, 2000) using the fast Fourier transform algorithm. Fig. 1 shows an example of random fields generated for a model of a steam flooding test performed at creosote-contaminated site at Visalia, California (Newmark et al., 1999). Here, three random fields were generated, one for each zone. The air entry pressure parameter for the capillary pressure curves were also varied spatially by assuming that they scale as the square-root of the permeability.

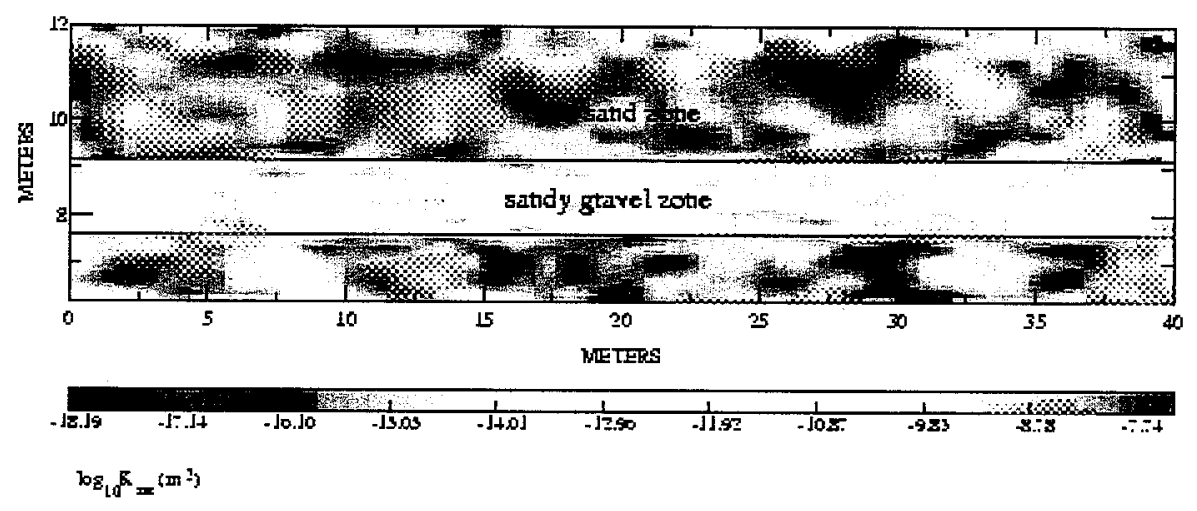

Fig. 1 Heterogeneous random fields generated for saturated intrinsic permeability. Model was used to perform simulations of steam flooding test performed at creosote-contaminated site at Visalia, California (Newmark et al., 1999).

A multi-continua option was implemented into NUFT, which enables the code, for example, to 
model sites with fractured porous rock by treating the fracture network and the porous rock matrix as separate porous medium continua. Theoretically, any number of continua can be specified to model separate fracture sets. Exchange of fluids between continua is governed by various flow options. The random field generation also works with this capability. In particular, each continua can have material types with each material type having up to three statistically-independent random fields. The file addendum.doc distributed with the NUFT code documents the multi-continua and random property field options. Fig. 2 shows the isosurface of 50 percent liquid water saturation (saturation is the fractional occupied void space) in the fractures due to infiltrating water within a heterogeneous domain.

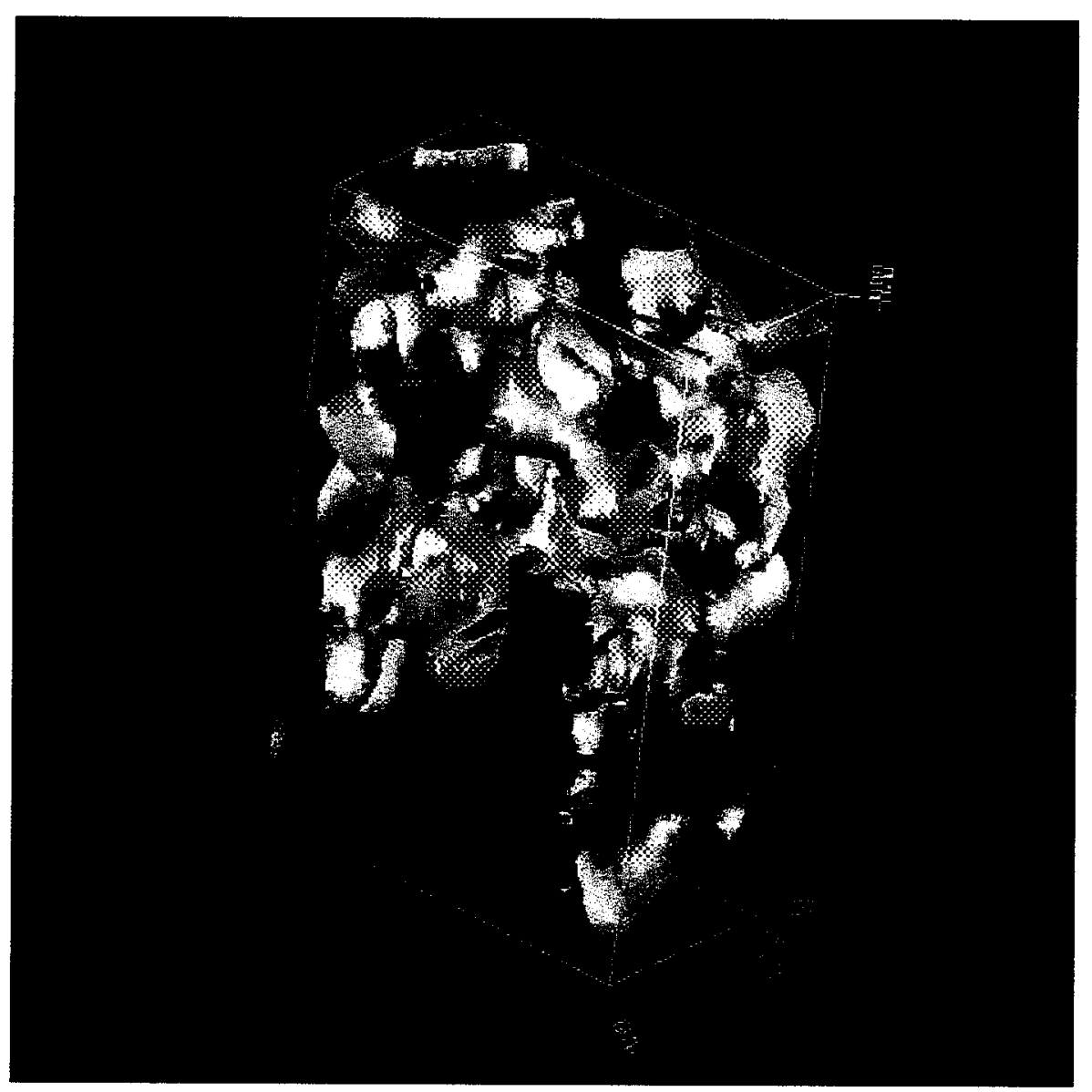

Fig. 2 Water infiltrating within a heterogeneous fracture continuum. The 50 percent liquid water saturation isosurface is shown. 


\section{Model Validation}

A primary objective of this project was to validate NUFT for soil vapor extraction (SVE). Code enhancements and general support provided by this project contributed either to the preparation and documentation of other validation efforts. A broad suite of validation tests is preferable to a single test because each one is able to focus on a subset of processes modeled in NUFT. We will therefore describe the results of these other field validation exercises as well.

\section{Validation of Soil Vapor Extraction at the LLNL B-518 Site}

A detailed description of the soil vapor extraction validation at the LLNL Building 518 (B-518) site is given in Nitao et al. (2000). Soil vapor extraction is a commonly-used remediation method for removing volatile organic contaminants (VOCs) from the vadosezone. Soil gas is extracted from the subsurface by applying a vacuum to one or more boreholes. In many cases, air is also injected at other locations to enhance overall flow rates.

B-518 was constructed in 1958 and used as a gas cylinder, solvent drum, and oil drum facility. Several sites around the former facility were identified to have potentially high concentrations of VOC, primarily trichloroethylene (TCE). In 1993 a two-day field test was performed at a borehole located in the area of the highest soil concentrations to demonstrate the treatability of the site. The mean permeability of the model was calibrated based on the wellhead pressure and the total extracted vapor flux. The initial total contaminant mass was calibrated using the vapor concentrations from the borehole. The shape of the vapor concentration history curve agreed well with calibrated model predictions (see Fig. 3). It was found that the initial mass had to be increased up to five times the initial estimates using simple spatial interpolation, indicating that initial estimates were probably too low.

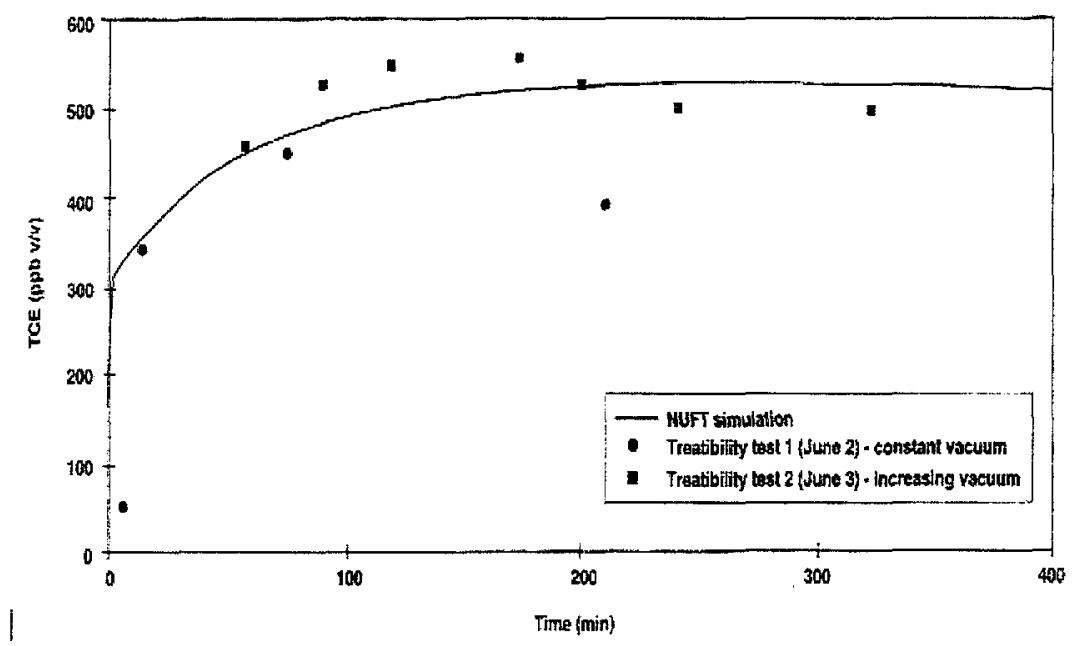

Fig. 3 Comparison of SVE vapor concentrations from calibrated model with field data during the pre-remediation test.

In September 1995, actual remediation of the site was begun using vapor extraction from the same 
borehole. We decide to model the remediation using the model calibrated in 1993 . We focused on the first 19 months of extraction because after that period other extraction boreholes began operation, which would extend the range of remediation beyond that of the 1993 calibration. The total vapor flux history measured in the field was input to the calibrated NUFT model in the form of a specified flux well condition. The resulting comparison with the field and model prediction is shown in Fig. 4.

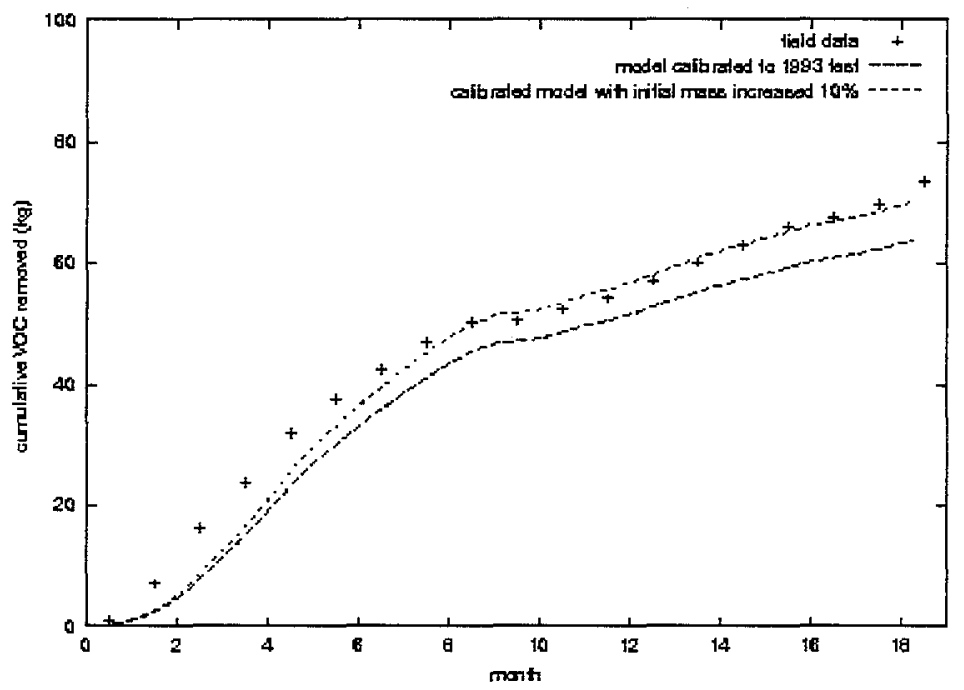

Fig. 4 Comparison of cumulative total VOC mass from field measurements with TCE predicted by the model during the first 19 months of SVE, beginning September 1995. Increasing the initial mass in the model by $10 \%$ shows the sensitivity to the mass estimate. Most of the VOC stream is TCE, but other relatively minor volatile contaminants that are present, but not included in the model, will cause total VOC to be under predicted.

Using the same homogeneous model that was calibrated against the two-day treatability test in 1993, we obtained very good agreement with the produced stream obtained during the first 19 months of remediation using SVE from the same well. Although the main goal of the study was model validation against SVE, we also showed in the report how a numerical model can be used to improve initial contaminant mass estimates. 


\section{Modeling Gaseous Transport for Nuclear Treaty Verification}

On September 22, 1993, at the Nevada Test Site on Rainier Mesa, 1.3 million kilograms of chemical explosives was detonated in a mined cavity situated at a depth of $400 \mathrm{~m}$ below the ground surface (Carrigan et al., 1996). The purpose of the explosion was to investigate the transport of detectable gases that would be released during a clandestine nuclear test explosion. The test simulates a nuclear explosion with a yield of 1 kilotonnes. A gas bottle containing $1.3 \mathrm{~m}^{3}(\mathrm{STP})$ of helium-3 $\left({ }^{3} \mathrm{He}\right)$ and second gas bottle containing $8 \mathrm{~m}^{3}(\mathrm{STP})$ of sulphur hexafluoride $\left(\mathrm{SF}_{6}\right)$ was placed into the cavity before loading the explosives to act as tracers. The geologic formation at the site consists primarily of tuffaceous rock of varying degrees of fracturing. The cavity is located in the unsaturated zone. Fig. 5 shows the location of the cavity that is in the vicinity of a highly-fractured zone that is depicted.

Almost 200 gas samples were obtained at the ground surface over a period of 500 days and analyzed. Barometric cycling was found to be the primary driver for gas tracer movement from the cavity to the ground surface. This transport mechanism is a combination of the advective process in the fracture and the diffusive process within the rock matrix. The center plot in Fig. 6 is the barometric pressure over the period of measurement. The measured pressure was input into the model as a time-dependent boundary condition. The upper plot is the predicted sulfur hexafluoride concentration in parts per trillion (volume/volume), and the lower plot is the predicted helium-3 concentration.

The yellow-colored circles correspond to positive hits of sulfur hexafluoride and the red-colored circles are those for helium-3. Because the average aperture of the fractures was unknown, this model parameter was calibrated based on the first positive hit of helium- 3 on $10 / 6 / 94$. This value was then used in the model for calculating the sulfur hexafluoride concentration. Note that the time when the concentration first breaks above the detectable limit agrees with the time, $11 / 10 / 93$, when the first break-through if measured, validating the accuracy of the model. The conclusions of the study was used for determining the required observational duration for the monitoring of nuclear test ban treaties. 


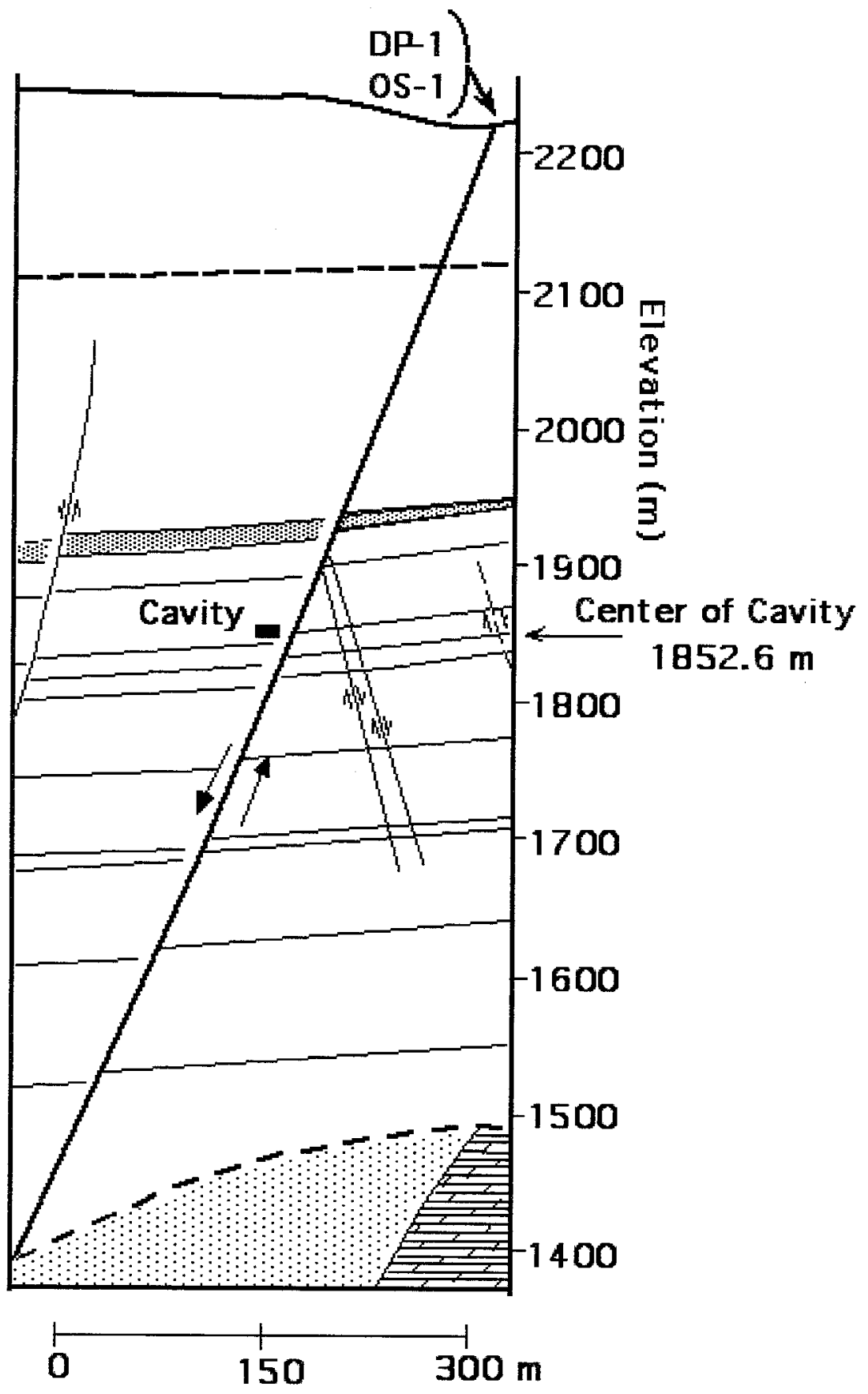

Fig. 5 Cross-section of the Rainier Mesa showing location of the cavity where the explosion was detonated. A nearby fractured zone is also shown. 


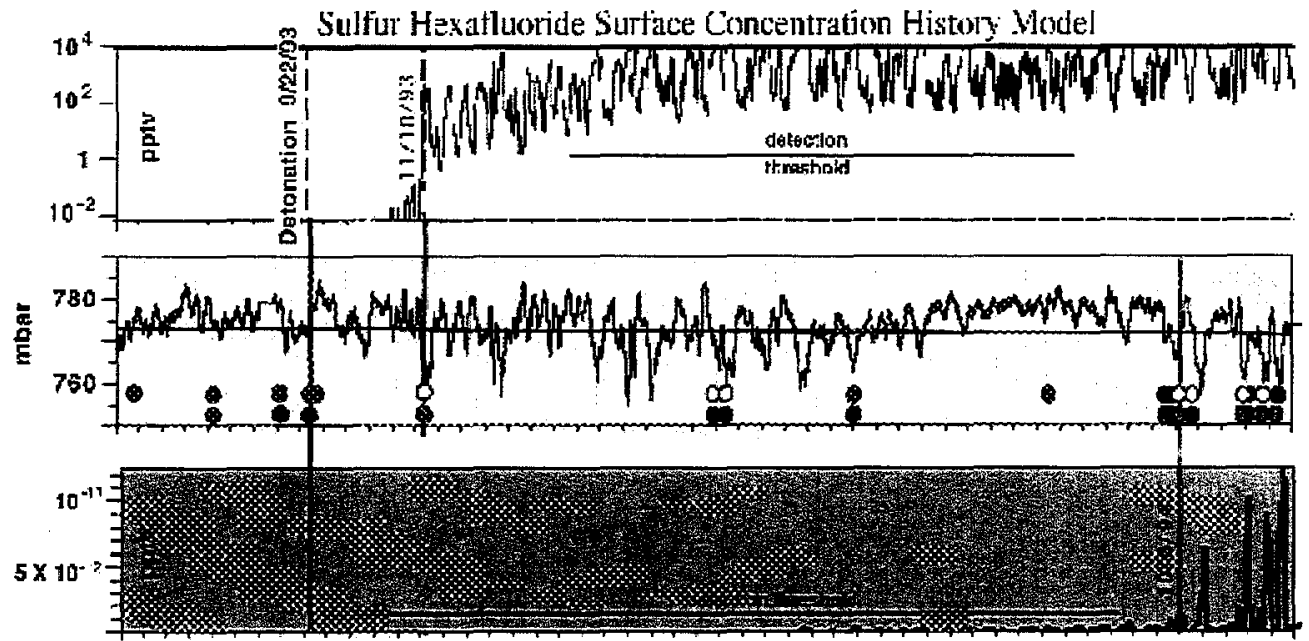

Helium-3 Surlace Concentration History Model

Fig. 6 The upper plot is the surface concentration of sulfur hexafluoride predicted by the NUFT model. The next plot shows the barometric pressure at Rainier Mesa during the time period. This pressure was used as a boundary condition to the model. The last plot shows the predicted surface concentration of helium- 3 . The black dots in the figure are negative concentration measurements. The yellow dots are positive hits of sulfur hexafluoride, and the red dots are positive hits for helium-3. 


\section{Modeling Infiltration at the CAMBRIC Trench Site}

The groundwater near the CAMBRIC nuclear test of 1965 at the Nevada Test Site was steadily pumped for a period of 16 years beginning in 1975 in order to understand how test-related radionuclides could migrate in groundwater. The water and radionuclides produced from this well were continuously monitored and tested, but otherwise released into an unlined trench at the ground surface and allowed to discharge towards Frenchman Lake. The water was also able to infiltrate into the unsaturated soil beneath the trench, creating a distinctive moisture and radionuclide plume in the vadose zone and eventually reaching the water table at a depth of 200 meters. A team at LLNL consisting of A.F.B. Tompson, D.K. Smith, S.F. Carle, and G.B. Hudson, has been investigating the site in order to increase scientific understanding of vadose zone flow and transport processes.

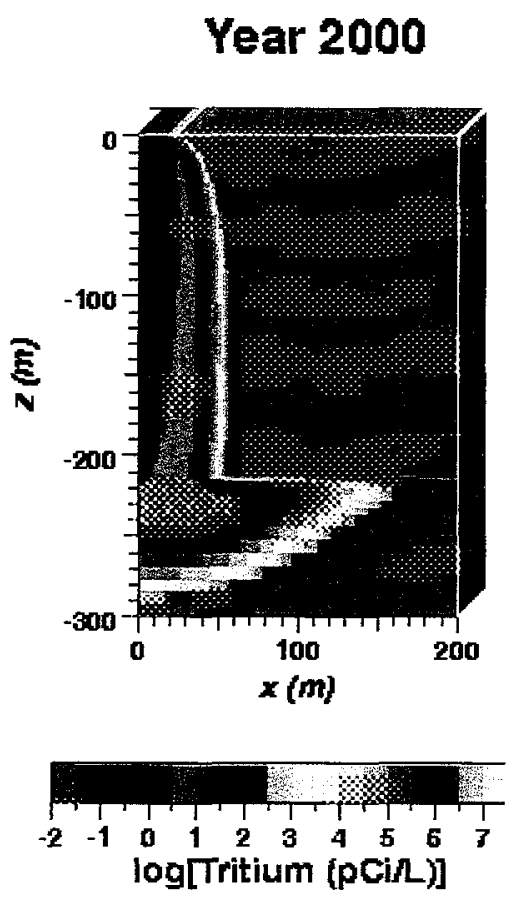

Fig. 7 Tritium concentrations at year 2000 for the CAMBRIC trench study predicted by NUFT. The red vertical line represents the location of a well where concentrations are being sampled (Figs. 7 through 10 are courtesy of S. Carle). 
Groundwater samples collected near the water table from a monitoring well located 106 meters from the trench have been analyzed for the presence of discharged radionuclides for a several years. As an initial step in analyzing the system, a two-dimensional model of unsaturated flow and transport of tritium was developed using the NUFT USNT module configured for isothermal conditions, with a gaseous phase and an aqueous phase, and three components: non-tritiated water, tritiated water, and air. The geological system consists of unconsolidated alluvium. Fig. 7 shows the predicted plume of aqueous tritiated water concentration at year 2000. The location of the monitoring well Ue5n is also shown. Fig. 8 compares the predicted concentrations of tritium versus the measured values sampled from well Ue5n as a function of time. There is excellent agreement between model predictions and field data.

\section{Tritium Measured at Well}

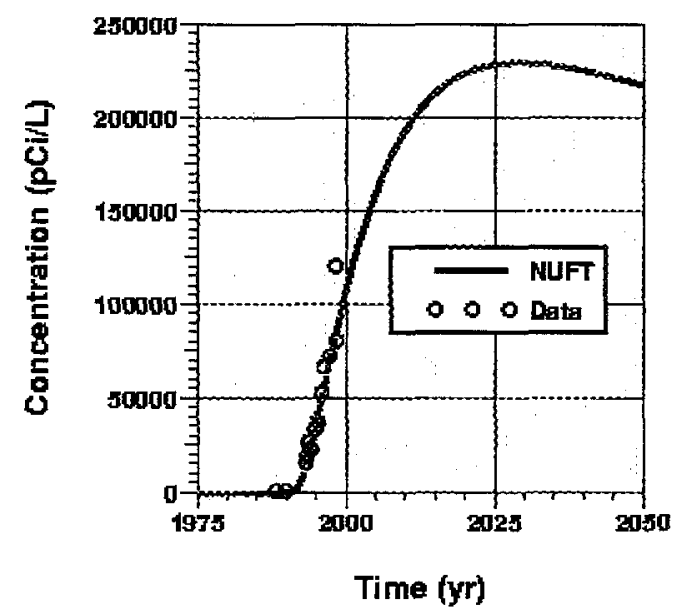

Fig. 8 Comparison between NUFT predictions and measured concentrations of tritium at the monitoring well for the CAMBRIC trench study. 


\section{Simulation of the Thermal Signature from an Underground Nuclear Test}

The U.S. Department of Energy is currently investigating the release and transport of radionuclides resulting from underground nuclear tests at the Nevada Test Site as part of the Underground Test Area Project. One focus of the investigation is a test called Cheshire that took place at the Nevada Test Site on February 14, 1976. The announced yield of the test was 200-500 kilotons of equivalent TNT. The detonation point was at a depth of 1167 meters, which is below the depth $(542 \mathrm{~m})$ of the water table on Pahute Mesa. The estimated mean groundwater flux of the aquifer is 0.003 cubic meters per square meters per day (Maxwell et al., 2000). The geologic formation consists of fractured volcanic rock with spatially-varying bulk permeabilities.

Much of the energy produced by the test becomes heat that is transported away from the detonation area over a period of many years. The physical processes responsible for heat movement are thermal conduction, thermal buoyant convection, and saturated zone advection from the regional groundwater gradient on Pahute Mesa. Being able to predict heat-driven flow is important because it can be the dominant mechanism for moving radionuclides away from the point of detonation. Also, when measured in the field, the time-dependent thermal signature resulting from heat movement is extremely valuable for estimating hydrologic properties of the disturbed environment surrounding the test, validating geostatistical characterizations of the undisturbed formation near the test, and for validating predictive computer codes.

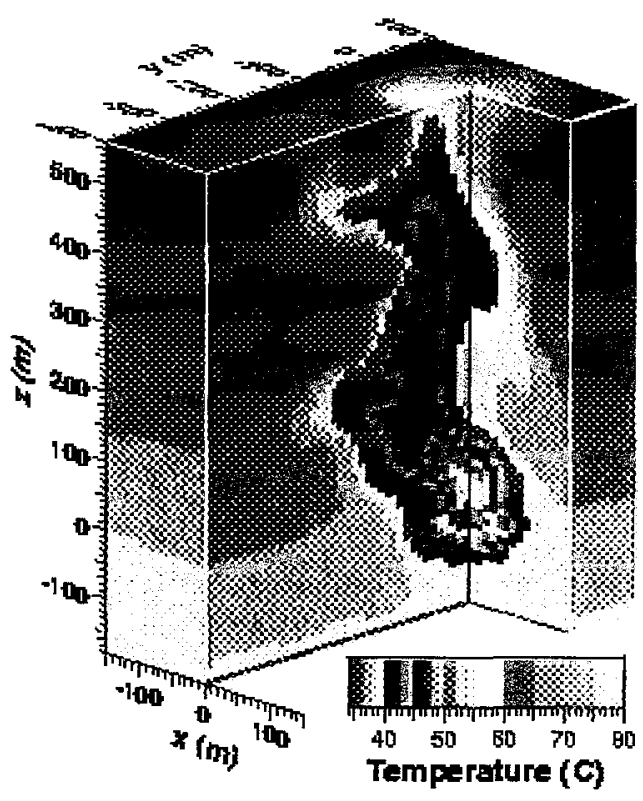

Fig. 9 Simulated temperatures 11.3 years after the Cheshire nuclear test. The observation well is indicated by the vertical red line. 
LLNL is currently performing investigations of the physical and chemical transport of radionuclides at the Nevada Test Site using a variety of computer codes, including NUFT (Maxwell et al., 2000; Tompson et al. 2000). Fig. 9 shows a simulation of the temperature response around the Cheshire test at a snapshot 11.3 years after the test. The NUFT USNT module was used to perform the calculation. The higher temperatures in the region above the detonation point are caused by thermal buoyant convection of heated water, which occurs primarily within the high-permeability "chimney" created by collapse of rock above the explosion. The heterogeneous permeability field for the simulation is generated using the stochastic method described in Carle (1996) that honors the juxtaposition of lithologic types and the geologic data obtained from boreholes.

Fig. 10 shows the temperature profile in a well marked by the red line in Fig. 9. The circles are actual field measurements, and the solid curve is from the NUFT simulation. Excellent agreement between the field and calculated temperatures was achieved.

\section{Temperature in Well}

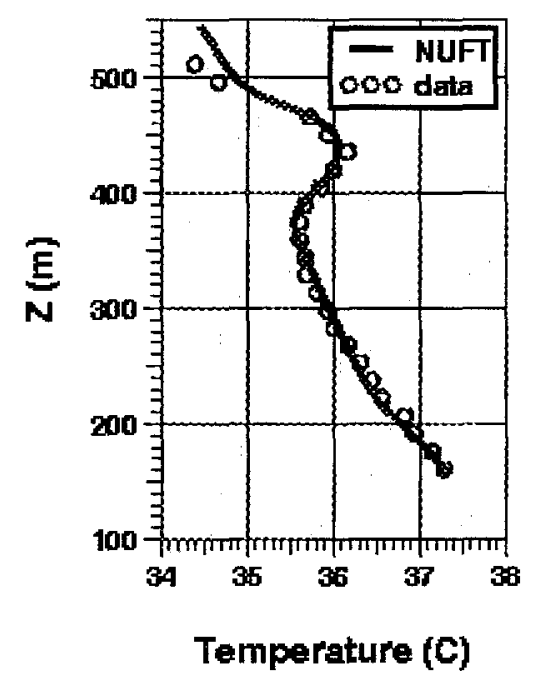

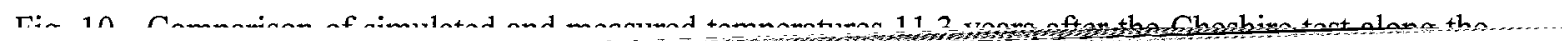




\section{Modeling Dynamic Steam Stripping -- the Visalia Test}

In the summer of 1997 a test was performed at Visalia, California which injected steam into a creosote contaminated formation (Newmark and Aines, 1998; Newmark et al. 1999). Sampling of water and monitoring of temperature was performed at an extraction well located 23 meters from the extraction well. A NUFT model was developed which incorporated heterogeneous distribution of hydrological properties as given by Fig. 1. The predicted breakthrough of the steam front at the extraction well was approximately 48 hours, which was very close to the observed breakthrough time.

Several noble gas tracers, were added to injected water and steam to track the movement of water and steam, and subsequently monitored at the extraction well. Fig. 11 shows the breakthrough curves at the extraction well from neon that was injected along with the steam. The different curves represent different initial conditions. The decrease in measured concentrations, as shown in the figure, that begins at 15 hours was caused by partial failure of the extraction well due to emulsification of NAPL. The NUFT model did not include the pump failure because its exact degree of impact is uncertain. Also, keep in mind that most of the simulations were done before the field test was actually performed. The agreement between field data and model prediction is considered to be good considering the complexities involved in the steam stripping process and the high degree of uncertainties involved in modeling a site that had relatively little quantitative characterization of hydrologic properties.

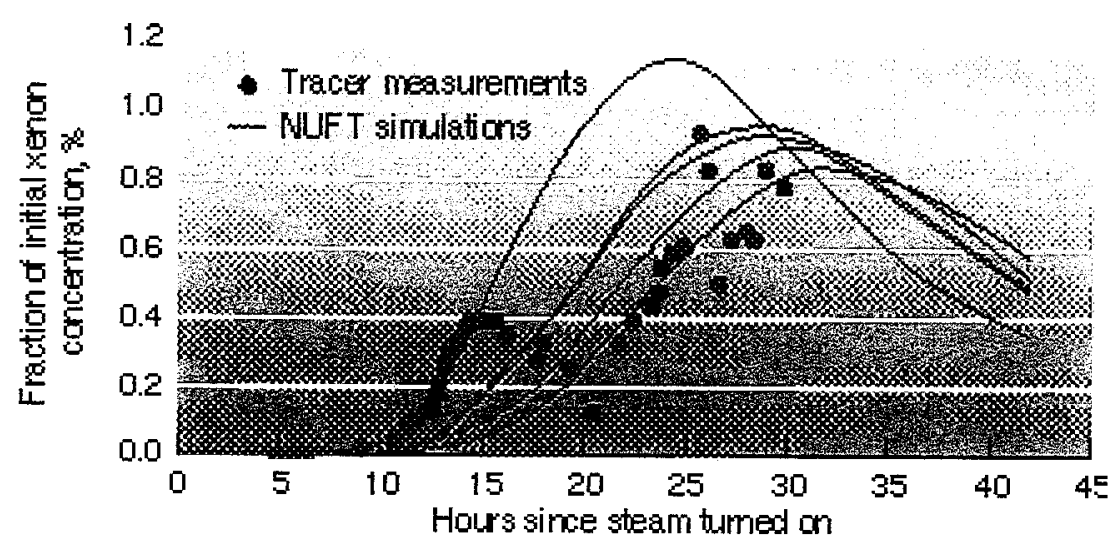

Fig. 11 Breakthrough curves for neon tracer that was injected with the steam (from Newmark and Aines, 1998). 


\section{Benchmarking of NAPL Movement and Steam Stripping}

NUFT has the capability to model heating of porous media through AC electrical heating (Carrigan and Nitao, 2000). LLNL has been performing scoping studies to model the enhancement of production from heavy oil reservoirs by this process (Sahni et al., 2000). The sponsor requested that NUFT be validated against an established petroleum industry reservoir simulator, in particular, the CHEARS code developed by Chevron Oil Company (Chien and Northrup, 1993). The selected test problem was the steam-flooding of a hypothetical reservoir.

Although this benchmarking exercise is not field validation, but is a verification exercise, we include it here because the CHEARS simulator is used by industry to make real-life field decisions of high degree of financial consequence.

CHEARS was run in this exercise as a black oil simulator, that is the petroleum is treated as a single non-volatile component. Because the NUFT USNT module cannot model a non-volatile component, the oil phase had small amounts of dissolved non-condensable gas.

The benchmark problem consisted of a three-dimensional rectangular domain $(109 \mathrm{~m}$ wide by $109 \mathrm{~m}$ deep and $18.3 \mathrm{~m}$ tall) with a steam injection well at the center and a fully-penetrating production well at each corner of the domain. The formation is a permeable sandstone with two low-permeability shale zones of thickness $1.524 \mathrm{~m}$, one starting at $3.05 \mathrm{~m}$ from the bottom of the model and $3.05 \mathrm{~m}$ from the top of the model. Steam is injected only in the sandstone between the two shale zones. The bottom and top of the model form impervious boundaries. The formation is tilted by 10 degrees from the vertical along one of the sides of the model.

Fig. 12 shows the shows the oil phase (NAPL) saturation at time 0.58 years from the start of the simulation for cross-section that runs through the injection well. The formation is tilted upwards going from the left to right. An oil bank, as indicated by the red, has developed around the steam injection well. The right portion of the bank that is shown has progressed farther because of the imposed tilt. The bluish zones are the shale zones that have very little oil saturation. Fig. 13 shows the plan view of the oil saturation at the same time period, at a horizontal plane underneath the upper shale zone, clearly showing the resulting oil bank.

Fig. 14 is the total oil flux and water flux produced from the field as predicted by the CHEARS and NUFT models. The under prediction of oil in the NUFT prediction as compared to the CHEARS model is probably due to the reduction in oil flow from evolution of non-condensable gas around production wells in the NUFT calculation. Comparison between the models is considered good, especially when compared to other industry code benchmarking exercises (Aziz et al., 1987). Note that differences can also arise from the manner in which the models control their time steps and other aspects of their numerical solution algorithms. 


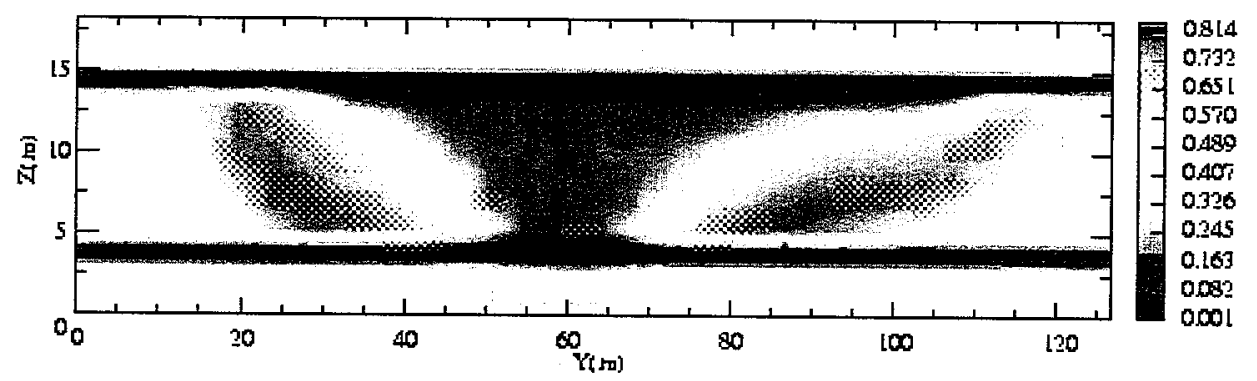

Fig. 12 Oil phase saturation along a vertical cross-section through the injection well parallel to the sides of the model. The model tilts upward by 10 degrees from left to right.

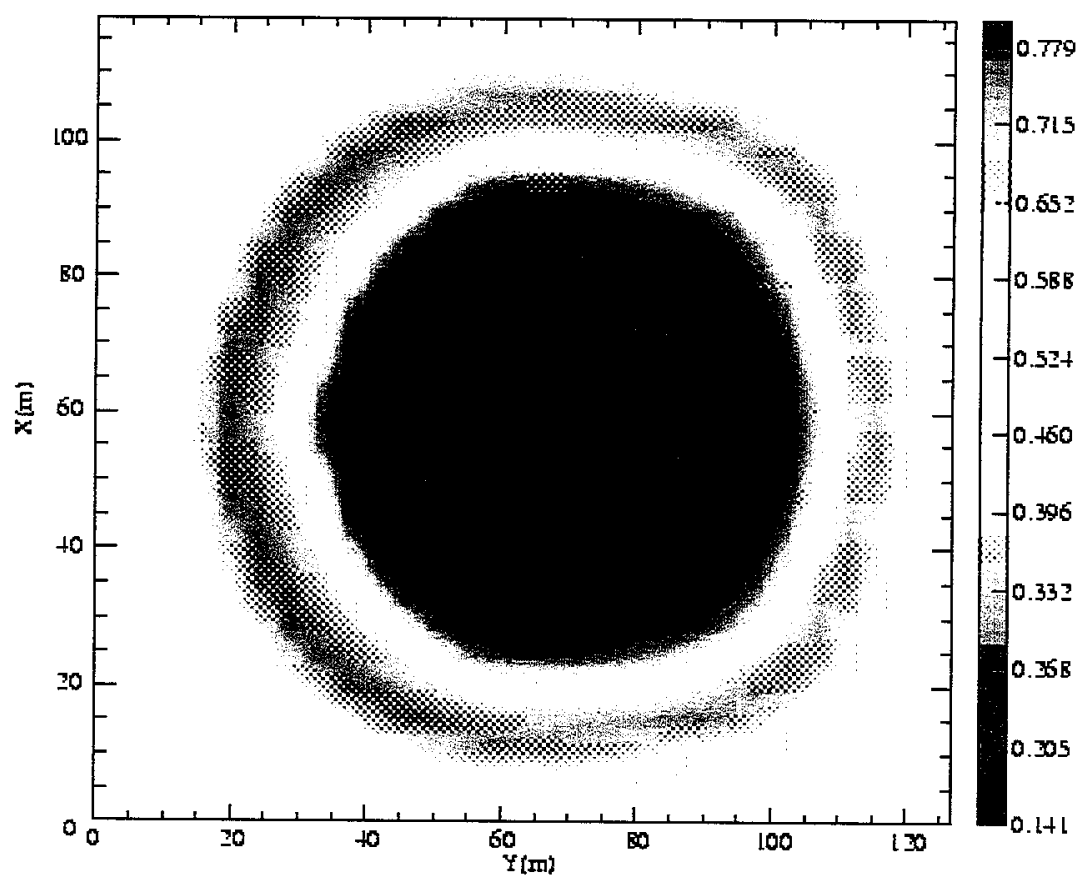

Fig. 13 Plan view of oil phase saturation in the sand layer just below the upper shale layer. The model tilts upwards from left to right. 


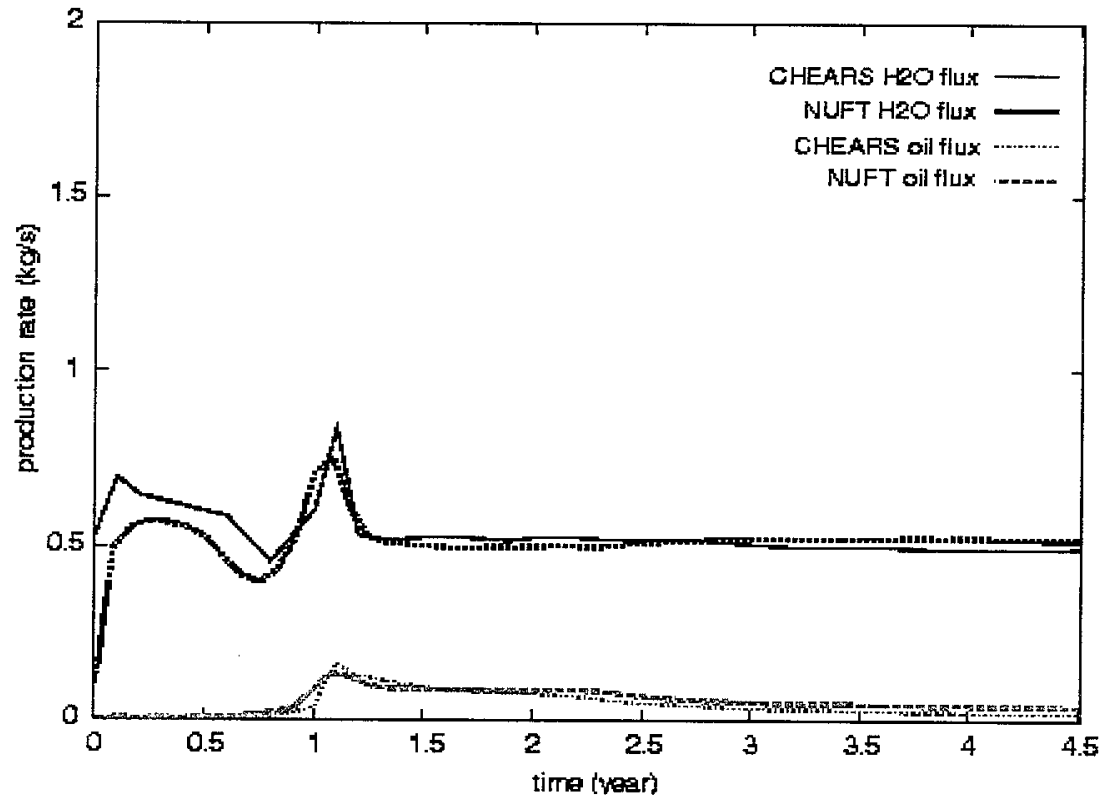

Fig. 14 Comparison of oil and water fluxes from the NUFT and CHEARS models (courtesy of R.Knapp). The differences are primarily due to the evolution of dissolved gas present in the NUFT model and different time stepping schedules. 


\section{Modeling of Bioventing at Site 280, Hill AFB}

An initial modeling effort was performed for bioventing at Site 280 in Hill Air Force Base, which is located near Ogden, Utah. Bioventing is the remediation of hydrocarbons from the vadose zone by injecting air into the vadose zone in order to enhance aerobic biodegradation of hydrocarbons from naturally-occurring microbes. Compared to SVE, the required flow rates are low. The vadose zone at Site 280 is contaminated with jet fuel.

The components modeled were water, $\mathrm{N}_{2}, \mathrm{O}_{2}, \mathrm{CO}_{2}$, and benzene $\left(\mathrm{C}_{6} \mathrm{H}_{6}\right)$. All components can partition into both gaseous and aqueous phases, which, for example, allows for evaporation of water and dissolution of benzene in the aqueous phase. Both diffusive and advective transport of all components in both fluid phases is considered. Since no NAPL has been observed at the site, no free phase was considered.

Stochiometry of the biodegradation process was described by the following reaction

$$
\mathrm{C}_{6} \mathrm{H}_{6}+7.5 \mathrm{O}_{2}=\Rightarrow 6 \mathrm{CO}_{2}+3 \mathrm{H}_{2} \mathrm{O}
$$

An irreversible dual-substrate Monod reaction kinetics was used to model this reaction. The coefficient for the rate equation was calibrated based on plume size and total mass removal.

Modeling without bioventing showed, as expected, that biodegradation, is limited by the lack of oxygen. Natural biodegradation was predicted to destroy $15.4 \%$ of the contaminant mass while bioventing will destroy $99.6 \%$. Further work ended because of re-prioritization from the mid-project program review. A report by Sun et al. (2000) was written to document this exercise. 


\section{Integration with the GMS Program}

A sophisticated NUFT interface for GMS (2000) was developed by the Bringham Young University using information about NUFT input from this author. Because most environmental remediation methods modeled by NUFT uses the USNT module, it was decided to implement only this module at this time.

Because of the many options available in NUFT and because of its generality, considerable programming effort was required to program the GMS NUFT interface. It is outside the scope of this section to detail this effort here.

Some modifications to the NUFT code, itself, were also required. Because NUFT was originally written to be run at the MSDOS or Unix command line, instead of interactively under a graphical GUI, such as GMS, various modifications had to be made to the NUFT code.

First, a new output option into NUFT was implemented and tested which allows NUFT to create output files in the standard GMS binary output format so that GMS can read NUFT output directly for graphical output. The output times for the data can be specified by the user through the GMS interface. Next, NUFT and its program build system were ported from the GNUC+ compiler to the Microsoft Visual $\mathrm{C}++$ compiler in order to support long file names under Windows NT.

NUFT assumes that all user output files should be created in the directory in which it being run; whereas, GMS passes the full directory path of the input file and expects all output files to go in the directory of the input file. A function supplied by BYU to extract the executable and input file directory paths was integrated into NUFT in order to be consistent with the GMS convention. A similar change was made with regards to the directory location of the NUFT start-up files, which is now based on parsing the full directory path of the NUFT executable. All of these changes had to be made while maintaining compatibility with non-personal computer platforms.

The following directions on building a NUFT model using GMS are from the GMS help utility.

Building a NUFT Simulation

1. A NUFT model is typically constructed in GMS using the following steps:

2. A cell-centered 3D grid is constructed.

3. The basic NUFT options are selected including general options, equations, time steps, solver, etc.

4. Regions of the grid are selected and marked as ranges.

5. All boundary conditions and sources/sinks are assigned to ranges.

The ranges also define material zones. 
6. The material, phase, and component properties are defined.

7. Boundary conditions and phase and component sources are assigned to predefined ranges.

8. Wells are created and assigned the appropriate phase and component fluxes.

9. Initial conditions are defined.

10. Output control options are selected.

11. The model is saved and NUFT is launched from the GMS menu.

12. The NUFT solution is read into GMS for post-processing.

An existing NUFT simulation can be read into GMS using the "Read Simulation" command in the NUFT menu. Once a NUFT simulation is saved to disk, NUFT can be launched by selecting the "Run NUFT" command from the NUFT menu. The command brings up a dialog listing the path to the NUFT executable and the most recently saved NUFT simulations. In most cases, these paths do not need to be edited. When the "OK" button is selected, NUFT is launched and the input file is passed to NUFT as a command line argument. NUFT is launched in a separate window and the console output from NUFT is displayed. Fig. 15 shows an example dialogue menu for specifying the phase-dependent material properties of a NUFT material type.

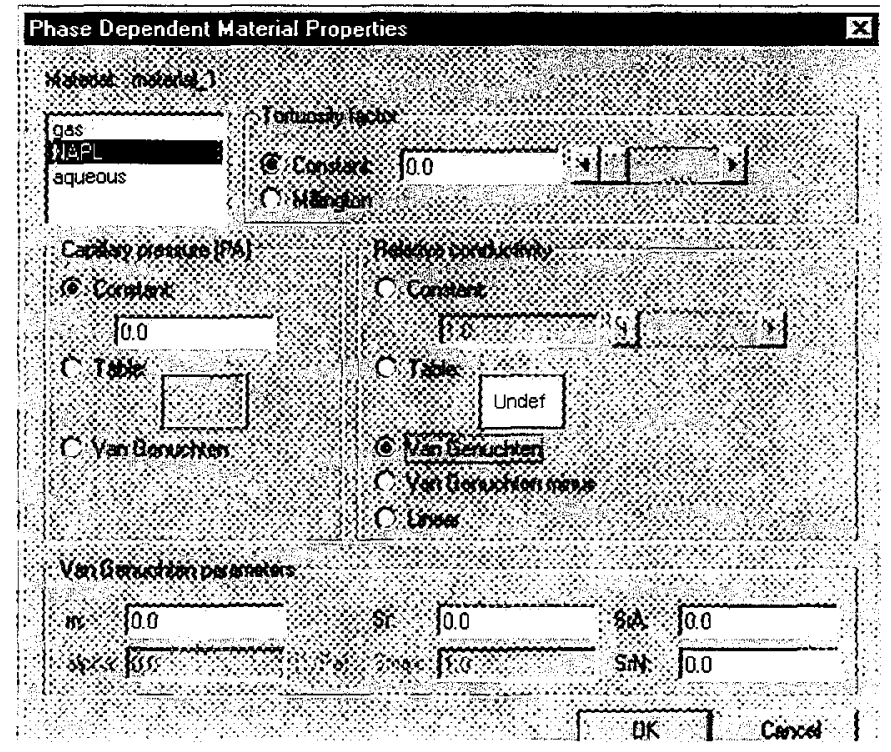




\section{Recommendations}

Because multiple flow and transport mechanisms occur during most remediation processes, preferably more than one field test should be used to verify computer models. Each test in a broad suite of tests can be used focus the validation on a particular subset of dominant processes.

Table 1 is a matrix diagram listing various physical processes modeled by NUFT with check marks indicating appropriate tests validating each process. If a process plays only a minor role in a test, it is not checked. For example, aqueous phase transport due to infiltration occurs in the LLNL B-518 SVE remediation test, but at that site it is unimportant relative to gaseous phase transport, so it is not marked. However, in less arid regions, aqueous phase transport can play a significant role in contaminant transport during SVE, at least during periods of high rainfall. Aqueous phase transport is an important part of SVE in such circumstances. Thus, it is important that we have other tests, such as the trench infiltration test, for validating aqueous phase advection, even if these tests are not SVE tests. Some of the other tests such as the nuclear treaty verification test is important for SVE because it validates gaseous advection and diffusion processes which are the same primary transport processes occurring in SVE. However, one difference is that this test took place in fractured media.

The Visalia field test and the steam-flood simulator test are important for modeling thermal remediation processes and for problems where there is NAPL movement. NAPL movement is important at SVE sites where there is free product.

The results of the validation tests modeled by NUFT were very encouraging. Although it is impossible to rigorously prove the validity of NUFT or any computer code, for that matter, the tests that were performed give confidence that the code can be used for modeling SVE, thermal remediation methods such as dynamic steam stripping, and general prediction of vadose zone flow and transport processes. 
Table 1 Process Validation Matrix

\begin{tabular}{|c|c|c|c|c|c|c|}
\hline & \multicolumn{6}{|c|}{ Field Tests } \\
\hline Main Processes Validated & $\mathbf{A}$ & B & $\mathrm{C}$ & $\mathbf{D}$ & $\mathbf{E}$ & $\mathbf{F}$ \\
\hline Gaseous flow & $\mathrm{X}$ & $X$ & $\mathrm{X}$ & & $\mathrm{X}$ & \\
\hline Gaseous transport & $\mathrm{X}$ & $\mathrm{X}$ & & & $\mathrm{X}$ & \\
\hline Aqueous flow & & & $\mathrm{X}$ & $\mathrm{X}$ & $X$ & $\mathrm{X}$ \\
\hline Aqueous transport & & & $\mathrm{X}$ & $\mathrm{X}$ & $\mathrm{X}$ & $\mathrm{X}$ \\
\hline NAPL flow & & & & & & $\mathrm{X}$ \\
\hline Steam flow & & & & & $\mathrm{X}$ & $\mathrm{X}$ \\
\hline Steam transport & & & & & $\mathrm{X}$ & \\
\hline Thermal advective transport & & & & $\mathrm{X}$ & $\mathrm{X}$ & $\mathrm{X}$ \\
\hline Thermal conductive transport & & & & $\mathrm{X}$ & $\mathrm{X}$ & $\mathrm{X}$ \\
\hline Fluid phase changes & & & & & $\mathrm{X}$ & $\mathrm{X}$ \\
\hline Heterogeneous systems & & & & $\mathrm{X}$ & $\mathrm{X}$ & \\
\hline Barometric pumping effects & & $\mathrm{X}$ & & & & \\
\hline Transport in fractures & & $\mathrm{X}$ & & & & \\
\hline Infiltration flow & & & $\mathrm{X}$ & & & \\
\hline Infiltration transport & & & $\mathrm{X}$ & & & \\
\hline Injecting and producing wells & $X$ & & & & $\mathrm{X}$ & $\mathrm{X}$ \\
\hline
\end{tabular}

Field Tests

A. LLNL B-518 SVE remediation

B. Nuclear treaty test

C. CAMBRIC trench study

D. Cheshire nuclear test

E. Visalia field test

F. Steam-flood simulator benchmark 


\section{References}

Aziz, K., A.B. Ramesh and P.T. Woo (1987). Fourth SPE Comparative Solution Project - A Comparison of Steam Injection Simulators, Journal of Petroleum Technology, vol. 39, No 12, pp. 1576-1584.

Carle, S. F. (1996), A Transition Probability Approach to Geostatistical Characterization of Hydrostratigraphic Architecture, Ph.D. Thesis, Hydrologic Sciences Graduate Group, University of California, Davis.

Chien, M. C. H. and E. J. Northrup (1993), Vectorization and Parallel Processing of Local Grid Refinement and Adaptive Implicit Schemes in a General Purpose Reservoir Simulator, paper presented at the 12th SPE Symposium on Reservoir Simulation held in New Orleans, LA, U.S.A., February 28-March 3, 1993, SPE paper no. 25258.

Carrigan, C.R., R.A Heinle, G.B. Hudson, J.J. Nitao, and J.J. Zucca (1996), Trace Gas Emissions on Geological Faults as Indicators of Underground Nuclear Testing, Nature, vol. 382, 528-531.

Carrigan, C. R. (1999), Understanding the fate and transport of multiphase fluid and colloidal contaminants in the vadose zone using an intermediate-scale field experiment Lawrence Livermore National Laboratory Report No. UCRL-JC-133819.

Carrigan, C.R., and J.J. Nitao (2000), Predictive and Diagnostic Simulation of In Situ Electrical Heating in Contaminated, Low-Permeability Soils, Environmental Science and Technology, vol. 34, No. $22,4835-4841$.

Demir, Z, L. Ferry, L.K. Green-Horner, V. Madrid, M. Maley, K. Mansoor, and S.V. Haar (1999), Assessment of impact to ground water from vadose zone sources for the site 300 site-wide feasibility study, Lawrence Livermore National Laboratory Report No. UCRL-AR-135312.

GMS (2000), Groundwater Modeling System, www.gms.watermodeling.org.

Lee, K. and J.J. Nitao (2000), Geostatistical characterization and numerical modeling of the vadose zone transport of tritium released from an underground storage tank, Lawrence Livermore National Laboratory Report No. UCRL-JC-131756.

Maxwell, R.M., A.F.B. Tompson, J.T. Rambo, S.F. Carle, and G.A. Pawloski (2000), Thermally Induced Groundwater Flow Resulting from an Underground Nuclear Test, Proceedings of the XIII Computational Methods in Water Resources Conference, Calgary, Canada, June 25-29, 2000, A.A. Balkema Co., Rotterdam Netherlands, pp. 45-50,. 
Newmark, R. and R. Aines (1998), They All Like It Hot: Faster Cleanup of Contaminated Soil and Groundwater, Lawrence Livermore National Laboratory Report no. UCRL-ID-130186.

(also, Science and Technology Review, Lawrence Livermore National Laboratory, Livermore, CA, May 1998)

Newmark, R L, R.D. Aines, K.G. Knauss, R.N. Leif, M. Chiarappa, G.B. Hudson, C.R. Carrigan, J.J. Nitao, A. Tompson, J. Richards, C. Eaker, R. Weidner, and T. Sciarotta (1999), Visalia Field Tests, Lawrence Livermore National Laboratory Report No. UCRL-JC-136771.

Nitao, J.J. (1998), Reference Manual for the NUFT Flow and Transport code, Version 2.0, Lawrence Livermore National Laboratory Report No. UCRL-MA-130651.

Nitao, J.J. (1999), User's Manual for USNT module of the NUFT code, Version 2.0.1, Lawrence Livermore National Laboratory Report No. UCRL-MA-130653-REV-1.

Nitao, J.J. (2000), Some Examples of the Field Validation of the NUFT Subsurface Flow and Transport Code, Lawrence Livermore National Laboratory Report, under internal review.

Nitao, J.J., and T.A. Buscheck (1995), "Discrete-Fracture Modeling of Thermal-Hydrological Processes at Yucca Mountain and the LLNL G-Tunnel Field Test," in Scientific Basis for Nuclear Waste Management XLX, W.M. Murphy and A.K. Knecht (eds.), Materials Research Society, Boston, MA, pp. 747-754..

Nitao, J.J., S.A. Martins, and M.N. Ridley (2000), Field Validation of the NUFT Code for Subsurface Remediation by Soil Vapor Extraction, Lawrence Livermore National Laboratory Report No. UCRL-ID-141546.

Rueth, L. S., R.A. Ferry, R. A., L.K. Green-Horner, T.H. DeLorenzo (1998), Remedial Design document for the General Services Area Operable Unit treatment facilities, Lawrence Livermore National Laboratory, Site 300, Lawrence Livermore National Laboratory Report no. UCRL-AR-127465.

Sahni, A., M. Kumar, and R.B. Knapp (2000), Electromagnetic Heating Methods for Heavy Oil Reservoirs, Lawrence Livermore National Laboratory Report No. UCRL-JC-138802.

Sun, Y., Z. Demir, T. Delorenzo, and J.J. Nitao (2000), Application of the NUFT Code for Subsurface Remediation by Bioventing, Lawrence Livermore National Laboratory Report No. UCRL-ID-137967.

Tompson, A. F. B., C. J. Bruton, G. A. Pawloski, D. K. Smith, W. L. Bourcier, D. E. Shumaker, A. B. Kersting, S. F. Carle, and R. M. Maxwell, On the Evaluation of Groundwater Contamination from Underground Nuclear Tests, in review, Environmental Geology, 2000 (also: Lawrence Livermore National Laboratory, report UCRL-JC-140435). 